Instructions for authors, subscriptions and further details:

http://brac.hipatiapress.com

\title{
El Arte como Resistencia. La Ópera-Tango María de Buenos Aires
}

Carlos L. Bosch ${ }^{1}$

1) Universidad Nacional de las Artes, Buenos Aires. Argentina

Date of publication: February $3^{\text {rd }}, 2015$

Edition period: February 2015 - June 2015

To cite this article: Bosch, C.L. (2014). El Arte como Resistencia. La Ópera-Tango María de Buenos Aires. Barcelona, Research, Art, Creation, 3(1), 59-72. doi: 10.4471/brac.2015.04

To link this article: http://dx.doi.org/10.4471/brac.2015.04

\section{PLEASE SCROLL DOWN FOR ARTICLE}

The terms and conditions of use, except where otherwise noted, are related to the Open Journal System and to Creative Commons Attribution License (CCBY). The indication must be expressly stated when necessary. 


\section{Art as Resistance. The Opera- Tango Maria of Buenos Aires}

Carlos L. Bosch

National University of Arts

(Received: 7 November 2014; Accepted: 7 Desember 2014; Published: 3 February 2015)

\section{Abstract}

On the shores of tango have landed large amount of literary and musical influences. Since its inception goer until the golden age, in the years 40 , the different orchestras were incorporating aesthetic of each period at the same time that were reflected in the great social changes of the twentieth century. In spite of this, the vast majority of the tangueros felt that Astor Piazzolla had crossed a boundary, had gone too far with his work, Maria de Buenos Aires. Not only is the first opera-tango of history, but that is one of the jobs where better reflects the differences and disputes toward the interior of the tango. While this work arises in an era where the artistic avant-gardes influenced the art scene in Buenos Aires, the defenders of the tango as traditional music of the city did not want to lose certain traditions that this gender jealously guarding her. We will analyze to what extent this work implies a resistance to the established conceptions of his time and how that resignification involves a series of changes that go beyond the tango.

Keywords: Tango, opera, resistance, Piazzolla, art 


\section{El Arte como Resistencia. La Ópera-Tango María de Buenos Aires}

Carlos L. Bosch

Universidad Nacional de las Artes

(Recibido: 7 Noviembre 2014; Aceptado: 7 Diciembre 2014; Publicado: 3 Febrero 2015)

\section{Resumen}

En las orillas del tango han desembarcado gran cantidad de influencias musicales y literarias. Desde su inicio prostibulario hasta la época de oro, en los años 40, las diferentes orquestas fueron incorporando estéticas de cada período al mismo tiempo que se hacían eco de los grandes cambios sociales del siglo XX. A pesar de ello, la gran mayoría de los tangueros consideraron que Astor Piazzolla había cruzado un límite, había ido demasiado lejos con su obra, María de Buenos Aires. No sólo es la primera ópera-tango de la historia sino que es uno de los trabajos donde mejor se reflejan las diferencias y disputas hacia el interior del tango. Si bien esta obra surge en una época donde las vanguardias artísticas influían en el panorama artístico de Buenos Aires, los defensores del tango como música tradicional de la ciudad no querían perder ciertas tradiciones que este género custodiaba celosamente. Analizaremos hasta qué punto esta obra implica una resistencia a las concepciones establecidas de su época y cómo esa resignificación involucra una serie de cambios que van más allá del tango.

Palabras clave: Tango, ópera, resistencia, Piazzolla, arte 


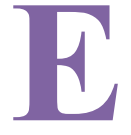

n 1956, Cátulo Castillo y Aníbal Troilo componen el último gran clásico del tango tradicional, La última curda, y ese mismo año Astor Piazzolla edita su primer éxito, Tres minutos con la realidad. Tal vez este sea el mejor símbolo, la fotografía donde se puede observar el momento donde un tango que ya estaba de vuelta se cruza con el tango de la renovación. Comenzaba una época de cambios y gran presencia de las vanguardias en todo el arte argentino. Declaraciones como la de Luis Felipe Noé, "es hora de elaborar nuestras propias vanguardias" (Giunta, 2001) o Aldo Pellegrini (1967), "-la vanguardia- contribuiría a sacudir la modorra un poco provinciana que aquejaba a nuestro arte", son una muestra de la impronta vanguardista que se vivía en Buenos Aires.

Piazzolla pertenece a una época donde se hacen difusos muchos límites, entre ellos, la diferencia tajante entre música popular y académica. George Gershwin en el jazz o Antonio Jobim en la Bossa Nova, llevaron adelante intentos similares y tuvieron que enfrentarse a los mismos prejuicios y críticas. Adiferencia de las vanguardias, ellos no se vanagloriaban de generar una ruptura o de cortar con las tendencias del pasado, por el contrario, querían modificar lo establecido sin romper con el género, sin dejar de ser Jazz, Bossa o Tango. Así, Piazzolla logró combinar una orquesta clásica con un Bandoneón, la armonía moderna con los ritmos arrabaleros y las formas instrumentales clásicas con la canción popular.

A partir de los años 60, Astor ya adquirió la experiencia suficiente como para romper los moldes de ambos mundos. Comienza a componer tangos para Orquesta de Cámara, para Cuartetos de Cuerdas y también una Ópera, María de Buenos Aires. Horacio Ferrer, en el año 65, le entrega el libreto de lo que llamaba Tango-Operita cuyo argumento relata la vida del tango desde su nacimiento, pasando por su infancia, la adolescencia multicultural, el esplendor de los grandes teatros, la decadencia, la muerte y, finalmente, su resurrección en el "nuevo tango". Encontró el discurso que le iba a permitir sostener la unión entre tradición y vanguardia pero también entre lo académico y lo popular. Gilles Deleuze (1987) afirma que el arte es un acto de resistencia y propone como ejemplo a Johann Sebastian Bach. En el siglo XVIII, la división de lo sensible proponía una separación absoluta entre lo sacro y lo profano. Bach fusiona estas dos instancias generando lo que Deleuze llama un acto de resistencia. Se resiste a aceptar el mundo establecido y propone una nueva mirada. Bach nos grita desde la historia su oposición a una partición insalvable entre lo 
sacro y lo profano. Piazzolla adopta la misma postura frente a las dicotomías de su época. Se resiste y propone una nueva división de lo sensible donde no hay separación entre lo académico y lo popular o la tradición y la vanguardia.

Las distintas miradas que vamos a desarrollar sobre María de Buenos Aires, se van a estructurar y van a contribuir con esta idea de acto de resistencia, concepto central a la hora de pensar la primera Opera-tango de nuestra historia.

\section{La Resistencia al Interior del Campo}

Dos días después del estreno, el diario La Nación (Anónimo, 1968) publicó la siguiente crítica referida a María de Buenos Aires:

Sobre un pretexto dramático se estructura este ejercicio musical en la que domina la inconfundible modalidad de Piazzolla - él mismo interpreta el bandoneón - y donde Horacio Ferrer - el propio narrador - desgrana una retórica casi inaprehensible, hecha de neologismos emparentados con el lunfardo. (p.71)

Cuarenta años después, el mismo diario (La Nación, 2008) decía lo siguiente:

A cuarenta años de su creación, la operita vive un gran momento y no deja de girar por el mundo. Ya pasó por unas cien ciudades y en la historia de la dupla formada por Piazzolla-Ferrer -una sociedad artística que duró veinte años- la ópera María de Buenos Aires es una de sus obras más interpretadas. Remediando esa larga deuda con la obra de Piazzolla-Ferrer, este año se realizarán dos estrenos locales de la operita. (p.2)

En estas dos críticas se hace patente el largo proceso de legitimación por el que tuvo que atravesar la ópera. Partiendo de una crítica soportada en la incomprensión de la obra hasta llegar al culposo reconocimiento de una deuda histórica con el artista. Pero las relaciones de fuerza que resultaron de esa disputa sólo se nos van a hacer visibles analizando la confrontación. Únicamente estudiando las posiciones, acciones, estrategias e instituciones involucradas podremos dimensionar las tensiones provocadas por esta 
resistencia.

Para tal fin, Pierre Bourdieu (1967) brinda un efectivo marco teórico que nos permitirá analizar las distintas posiciones frente al capital simbólico para luego determinar las relaciones de fuerza que surgieron en el interior del campo. Analicemos las diferencias entre lo que se da en llamar Tango tradicional y la propuesta de Piazzolla.

Para comenzar, en ambos estilos se legitiman valores diferentes. La tradición, el sonido, la rítmica tradicional -aferrados al tango de los años 40y la aceptación muy excepcional de algunos cambios -como los de Horacio Salgán- eran valores del tango tradicional. También se defendían las prácticas sociales de la milonga, el prestigio basado en la popularidad y la fuerte relación entre los integrantes de la orquesta, entre la orquesta y su público y entre la orquesta y su barrio de origen. Por el contrario, Piazzolla sostenía los valores de la evolución basada en dos justificaciones: la idea de enaltecer la cultura popular elevando su música y la decadencia que el tango sufría desde los años 50. Se reconocen viejos valores del tango pero sin aferrarse a ellos. El prestigio provenía de su alto nivel técnico y el éxito en el exterior. En este sentido, la ópera-tango es uno de los casos más representativos.

Uno de los grandes problemas que enfrentó Astor tuvo que ver con la falta de aceptación en las instituciones legitimadoras del género. También en este punto se ven diferencias importantes. Para el tango tradicional, el espacio por excelencia era la milonga pero igualmente se tocaba en clubes de barrio y en los carnavales. En términos mediáticos tenían presencia en la Radio -programas de tango o musicales-, muy poco en televisión y se habían publicado revistas de tango en los años 40 y 50 pero los 60 ya no se editaban. Las discográficas financiaban sobre todo programas de radio. Las más importantes del tango eran RCA Víctor, Odeón y Columbia. Se producía a medida que el público demandaba. La demanda se medía desde la radio y las disquerías. Piazzolla, a raíz de su nueva concepción y del rechazo por parte de este circuito, tuvo que desenvolverse en otro tipo de instituciones. Prefirió presentarse mayormente en teatros. Dentro de los medios tenía más presencia en los medios gráficos -suplementos culturales de diarios y revistas- y poca presencia en radio y televisión. Cada tanto se pasaba algún tema por la radio porque para ciertos programas significaba prestigio, como en Radio Nacional y Clásica. Hasta el año 69 no firmó con ninguna de las discográficas típicas del tango, tuvo que grabar con las de otros géneros: Phillips, La Trova y Polydor. Por ejemplo, María de Buenos Aires se grabó en La Trova. Tenía poco alcance nacional pero mucho impacto en el exterior. 
Desde ya, al defender diferentes valores, circuitos de difusión y concepciones del tango, los hábitos también eran disímiles. En las orquestas tradicionales, el director era la figura: Di Sarli, Darienzo, Troilo, Pugliese. Los ingresos de esas orquestas provenían básicamente de tres ámbitos: actuaciones en clubes, venta de discos y los derechos de autor por la reproducción de su música en radio y tv. Tanto las entradas como los discos tenían un precio superior al del resto de la música popular. Un músico podía durar muchos años tocando en una orquesta. La relación era laboral pero también personal -como si fuera un grupo de amigos-. Incluso en los peores momentos económicos, los directores de las orquestas se preocupaban para que sus músicos -los muchachos- no se queden sin trabajo. Algo fundamental es la prioridad que se le daba al baile y a la canción. Un buen tango, además de tener una buena melodía, tiene que poder bailarse. Se utilizaba la forma canción y los cantantes se especializaban en tango -eran cantantes de tango-. Las letras de las canciones utilizan un lenguaje poético aunque directo, tocando temas como el amor, la vida cotidiana o la realidad social.

En la renovación del tango las cosas se movían de una forma muy diferente. El instrumentista y compositor era la figura -Piazzolla, Salgán, Garello, Stampone-. Piazzolla tuvo varias formaciones: Quinteto, octeto, orquesta de cuerdas, etc. La relación con sus músicos se daba desde las necesidades compositivas -quinteto, octeto electrónico, etc- y laborales -contratos por el tiempo que duraba una gira-. Utilizaba la forma canción pero también incorporó estructuras clásicas como la Fuga, la Sonata, la Ópera etc. Los cantantes no provenían del tango -Susana Rinaldi, Amelita Baltar, Teresa Parodi- y los textos tienen una gran carga simbólica -en María de Buenos Aires llegan al surrealismo-. La mayor parte de los ingresos provenían de las giras y las ventas de discos en el exterior. Piazzolla, comenzó a venderse en Argentina luego del 68 con Balada para un loco aunque no lo hizo en forma sostenida. En este punto, al igual que el tango tradicional, los discos y las entradas para verlo eran caras en comparación con los precios de la música popular en general. El espacio donde más se nota la disputa con el tango tradicional es en el hecho de que Piazzolla sienta al público a escuchar tango, no se bailaba, y las melodías, todas instrumentales hasta el 68 , no eran fáciles de cantar.

La relación con el campo político fue sinuosa en ambos casos. Entre 1890 y 1920 el tango era prohibido en muchos ámbitos por chabacán. De 1930 a 1948 se censuran algunos tangos por deformar el idioma. Luego se dieron las prohibiciones políticas -Di Sarli por radical, Pugliese y Salamanca por 
comunistas, Hugo del Carril por peronista, etc-. Piazzolla sufrió censuras de presidentes de facto -Lanusse y Videla- por relacionarlo con las vanguardias que, a su vez, eran relacionadas con un supuesto pensamiento de izquierda y distorsiones al ser nacional.

Como pudimos observar, Piazzolla -y María de Buenos Aires en particulardiscute las reglas del campo en todos los aspectos: producción, distribución y consumo. Busca un cambio de mentalidad basado en una modernización de la estética tanguera, una idea de público donde el tango deja de ser una experiencia colectiva para disfrutarse en forma íntima y una concepción evolucionista del arte que tal vez haya dejado su rastro en parte de las generaciones posteriores pero que claramente todavía no estaba legitimada en los años 60 .

Esta ópera es el soporte material de una concepción que ya funciona como una apuesta en las luchas realizadas en ese campo de producción pero que aún no ha sido legitimado por sus instituciones -teatros, discográficas, medios de comunicación, público específico, etc-. Por lo tanto no ocupa una posición dominante y su resistencia queda expuesta al intentar redefinir los principios de dominación y legitimación del campo.

\section{La Resistencia en la Cultura}

A finales de los años 50, el sentimiento de post-guerra se hizo carne gracias al boom tecnológico, económico y cultural de la época, a raíz de lo cual, la ideología dominante pasó a ser el progreso. Se torna inevitable el trajín de las grandes ciudades, aumenta el acceso a medios de transporte, se afirma la televisión como el gran medio de comunicación y la juventud nace como grupo político, universitario y de consumo.

Puntualmente, en las fechas que rodean al estreno de María de Buenos Aires (mayo de 1968), se respira el cambio y la revolución. La Primavera de Praga en Checoslovaquia, París se agita con el Mayo Francés, la Guerra de Vietnam continúa su trágico curso, el cineasta Stanley Kubrick estrena 2001: odisea del espacio y The Beatles publican su polémico Álbum blanco.

Para Antonio Gramsci, las grandes transformaciones sociales son obra del hombre colectivo. Cuando el sistema entra en crisis surge la necesidad de construir una nueva voluntad colectiva que será el agente efectivo de la transformación social y funcionará como matriz de sentido. El nuevo proyecto comienza una guerra de posiciones donde buscará afirmarse como hegemónico. Tomando las propias palabras de Gramsci (1970): 
(...) todo acto histórico tiene que ser realizado forzosamente por el "hombre colectivo", es decir, presupone la existencia de una unidad "cultural-social" que junta para un mismo fin una multiplicidad de voliciones disgregadas, con la heterogeneidad de fines, sobre la base de una misma concepción del mundo. (pp. 20-21)

Ahora bien, si existe una resistencia es porque primero se había instalado una supuesta "normalidad". ¿Cómo se instala esa norma en la sociedad? Michael Foucault analiza el término a-normal (en su libro Los anormales) en torno a las cuestiones del saber y del poder. Considera que existe un "poder de normalización" que se ejerce a través de una serie de tecnologías de control. Esto es lo que permitirá la aparición, en consecuencia, de sujetos a-normales (los que no coinciden con la norma). Siguiendo esta misma idea podemos entender que la norma estética o la estética como disciplina normativa, ha actuado históricamente como parte del discurso hegemónico. Gracias a esto, la estética llega a la enseñanza en las academias, a los medios de comunicación y al resto de los aparatos institucionales característicos de cada momento económico y social cerrando así el trinomio de norma-saberpoder (Foucault, 1974):

Y, por último, creo que el siglo XVIII introdujo, con las disciplinas y la normalización, un tipo de poder que no está ligado al desconocimiento sino que, al contrario, sólo puede funcionar gracias a la formación de un saber, que es para él tanto un efecto como una condición de su ejercicio. (p.59)

Esos valores estéticos dominantes que se presentan como "normales", simplemente son el fruto de un contexto muy específico donde los metadiscursos del arte forman parte de la ideología dominante. Tomando el caso de Beethoven, observemos cómo algunos críticos de la época calificaron a su séptima sinfonía. De la Guarda (1986) publicó en su libro Las sinfonías de Beethoven, la siguiente crítica:

Música absurda y salvaje. El colmo de la deformidad. Un delirio donde no hay el menor rasgo de melodía ni armonía, ni un solo sonido que sea agradable al oído. Luego de esta sinfonía, deberían encerrar a Beethoven en un manicomio. (p.265) 
En ese contexto, la ideología dominante sostenía una norma estética la cual calificaba tanto a Beethoven como a su obra de "a-normal". Esta objetivación pasa a formar parte del "sentido público" de la obra y de la definición propia del creador.

Pero no se puede decir que esos conflictos sean de una clase social contra otra o de un sector contra otro. Son cambios que cruzan a toda la sociedad. Las clases y sectores interactúan y hacen muy complejas sus relaciones. Todos los grupos terminan influyendo sobre todos. ¿Cómo se articulan todas esas contradicciones y diferencias? Gramsci responde que es la ideología quien las regula y mantiene dentro del sistema. Ese es el espacio, el de la articulación, donde se da la lucha y la transacción, las victorias y las derrotas. Ahí se generan las correlaciones de fuerza entre las distintas concepciones y es por eso que todo hecho cultural es un hecho político. Parte de este proceso es expuesto por Gramsci (1999) de la siguiente forma:

Un tercer momento -de la conciencia colectiva- es aquel en que se alcanza la conciencia de que los propios intereses corporativos, en su desarrollo actual y futuro, superan el circulo corporativo, de grupo meramente económico, y pueden y deben convertirse en intereses de otros grupos subordinados. Esta es la fase más estrictamente política, que señala el tránsito neto de la estructura a la esfera de las superestructuras complejas, es la fase en la que las ideologías germinadas anteriormente se convierten en "partido", entran en confrontación y se declaran en lucha hasta que una sola de ellas tiende a prevalecer (...). (pp. 36-37)

El progreso tecnológico y la vanguardia artística forman parte de esa cultura dominante que intentaba articular los grandes cambios. En ese sentido, Piazzolla y los tangueros de la renovación formaban parte de un movimiento cultural más amplio que buscaba afirmarse como dominante. Ya comentamos al principio de este trabajo el hecho de que Piazzolla no busque la ruptura sino un vínculo que relacione el pasado del tango con su futuro -al igual que lo hicieran Gershwin o Jobim-. Toda obra, y María de Buenos Aires en particular, son la prueba del intento por articular distintos sectores de la cultura, por articular la vanguardia con la tradición, lo académico con lo popular o la Buenos Aires de los barrios con la del centro. Esta ópera es un símbolo, es una obra donde se logra materializar con mayor claridad esos valores y visones del mundo y, por lo tanto, donde queda expuesto este enfrentamiento por una nueva forma de producción, circulación, consumo y conducción del género. 


\section{Las Marcas de la Resistencia}

Lo político en el arte no sólo puede encontrarse en una proclama política concreta sino en su propuesta estética. La ruptura de la unidad de sentido dominante es, tal vez, el efecto político más profundo al que puede alcanzar una obra. Jacques Rancière (2005) entiende que la configuración de un nuevo espacio es lo político del arte:

Efectivamente, la política no es en un principio el ejercicio del poder y la lucha por el poder. Es ante todo la configuración de un espacio específico (...) la política es el conflicto mismo sobre la existencia de ese espacio, sobre la designación de objetos que comparten algo común y de sujetos con una capacidad de lenguaje común. (p.18)

En nuestro caso, la pregunta sería ¿Cuáles son, en María de Buenos Aires, las características que nos llevan a esa nueva división de lo sensible, a la ruptura en la unidad de sentido? No nos interesa tanto analizar las relaciones de fuerza que pudieran haber transformado la obra a posteriori sino las que actúan directamente en el momento de su concepción.

Para explicar este punto voy a utilizar como ejemplo a Frédéric Chopin. Este compositor no componía un preludio en abstracto que luego adaptaría a las ideas del romanticismo, Chopin componía directamente desde el romanticismo, con toda la red de ideas filosóficas, morales, políticas y estéticas que esto significa. Su obra es la materialización de esas ideas. Por lo tanto, las características estéticas de una obra y las características que luego supondrán una resistencia son las mismas. ¿Cuáles son las características del sonido Piazzolla? o dicho de otra forma ¿En qué puntos María de Buenos Aires es la materialización de una resistencia al consenso establecido? Para eso analizaremos las características de la obra desde su concepción.

Una de las primeras características que llama la atención es la utilización de la ambigüedad. Piazzolla forja una resignificación de elementos del tango y de la Ópera:

La primera y más obvia de las ambigüedades se encuentra al leer el nombre de los movimientos que componen la obra. Mezcla el lenguaje de la música clásica con el del tango: Tocata Rea, Tangus Dei, Tangata del alba, Fuga y misterio, Miserere canyengue de los ladrones antiguos en las alcantarillas.

Los instrumentos y voces utilizados son: orquesta de cuerdas, flauta traversa, guitarra, bandoneón, cantantes y coro. Esta formación se puede interpretar 
como una orquesta de cámara con bandoneón o como una orquesta de tango con coro. Sostiene la ambigüedad necesaria entre los dos géneros.

Los giros melódicos son claramente tangueros pero su ornamentación es clásica -especialmente Barroca-.

La línea de voz está escrita como para que sea cantada tanto por un cantante de ópera como por un cantante de tango.

Busca tratar temáticas tradicionales del tango como el amor, la traición o la vida de la calle pero sobre un argumento donde los personajes ocupan un rol totalmente simbólico como el porteño gorrión con sueño, la sombra de María, el coro de psicoanalistas o la voz de ese domingo -recursos del surrealismo no utilizado por el tango-.

En el léxico se encuentran giros del arrabal pero utilizando nuevos discursos. Por ejemplo, el tiempo es simbólico. No se puede decir que exista un tiempo del argumento ni un tiempo real. Transcurren en lo que podría ser un tiempo onírico.

Dentro de las novedades que propone esta Ópera, encontramos:

La estructura de la obra no es la de una Ópera clásica ni la de un tema popular. Se estructura en 2 actos compuestos de 8 canciones cada uno. Este esquema puede pertenecer tanto a la ópera antigua de Monteverdi -siglo XVII- como a los modernos musicales de Broadway.

Otro caso lo encontramos en la armonía. Utiliza progresiones de acordes típicas del Barroco pero con tipos de acordes provenientes del Jazz o el clásico contemporáneo -al estilo de Bartok-.

Utiliza frecuente del Riffs y Ostinatos típicos de la música popular del siglo XX.

Acordes tonales que se forman por cuartas -la melodía está en el bajo y los acordes por cuartas se escuchan en un registro más agudo-.

Genera colores armónicos típicos del impresionismo pero utilizando las funciones tonales del Jazz.

Entre el explícito simbolismo de los personajes y los permanentes monólogos dirigidos al público, se busca que la audiencia no entre en el juego de la ficción. Lo importante no es la identificación con los personajes sino con la historia.

Como podemos ver, esta ópera-tango fue concebida resignificando elementos de ambos mundos e introduciendo nuevas ideas de la vanguardia -tanto popular como clásica-. Ostenta una nueva designación de los objetos y la capacidad de generar un nuevo lenguaje en común entre los sujetos. Claramente abre un nuevo espacio político -en términos de Rancière- ya que 
se resignifica los elementos que la componen como la melodía, armonía, orquestación, personajes, estructura de la obra, léxico, etc- construyendo una nueva mirada sobre su mundo.

\section{Conclusiones}

En una entrevista realizada en Chile por Gonzalo Saavedra (1989), tres años antes de su muerte, Astor define esta obra como "música popular de cámara que viene del tango". Tal vez sea este el mejor ejemplo del concepto gramsciano de que la cultura no es homogénea ni sistemática sino el resultado de una compleja interacción entre grupos sociales. Los horizontes personales $\mathrm{y}$ colectivos se fusionan.

Como pudimos ver hasta ahora, los distintos géneros y estilos se influían unos a otros. De la decadencia del tango en los años 50 surge la propuesta de Piazzolla que, a su vez, estaba influenciada por las ideas de la vanguardia musical pero desde una concepción evolucionista que provenía de la música clásica. La ópera María de Buenos Aires parece tener el mismo origen caótico y contradictorio que su protagonista: "Diosa y atorranta, del cielo y del hampa fue trampa lo mismo, y atados de un pelo van su parte de cielo y su parte de abismo".

La famosa frase de Paul Klee (1964), "El arte no reproduce lo visible, hace visible", nunca estaría mejor aplicada que en este caso. En los años 30 y 40 el tango había hecho visible la vida cotidiana de vastos sectores sociales pero los años 60 necesitaban ser representados de otra forma. Las rupturas del arte no eran menos fundamentales que las sociales. El arte logró renombrar, reconceptualizar, resignificar, reorganizar y al hacerlo, ayudó a posicionar al sujeto en un lugar distinto al que el rol social le había predestinado. Al hacerlo, la obra se convirtió en un acto de resistencia. 


\section{Referencias}

Anónimo (1968, 10 de Mayo), Novedad Musical de Piazzolla y Ferrer, La Nación, 71.

Bourdieu, P. (1967), Campo intelectual y proyecto creador, Problemas de estructuralismo, México, Siglo XXI.

De la Guarda, E. (1986), Las sinfonías de Beethoven. Su historia y su análisis, Buenos Aires, Ricordi Americana S.A.E.C.

Deleuze, G. (1986), ¿Qué es el acto de creación?, Revista Fermentario, 6, 15.

Foucault, M. (1974), Los anormales, Buenos aires, Fondo de Cultura Económica.

Giunta, A. (2001), Vanguardia internacionalismo y politica, Buenos Aires, Paidos.

Gramsci, A. (1970), Introducción a la filosofía del a praxis, Barcelona, Ediciones Península.

Gramsci, A. (1999), Cuadernos de la Cárcel. Edición crítica del Instituto Gramsci, México, ERA.

Gramsci, A. (2004), Los Intelectuales y la Organización de la Cultura, Buenos Aires, Nueva Visión Argentina.

Klee, P. (1964), Schöpferische Konfession, Das Blindnerische Denken, Stutgart, Basel

Plaza, G. (2008, 6 de febrero), La obra de Piazzolla y Ferrer vuelve a renacer, La Nación, Sección Espectáculos, 2.

Pellegrini, A. (1967), Panorama de la pintura argentina contemporánea, Buenos Aires, Paidos.

Rancière, J. (2005), Sobre politicas estéticas, Barcelona, Servei de Publicacions de la Universitat Autónoma de Barcelona.

Saavedra, G. (1989, julio), Astor Piazzolla: Un tango triste, actual, consciente, El Mercurio, 42. 
Carlos L. Bosch: Universidad Nacional de las Artes.

Contact Address: Yerbal 1642, Ciudad Autónoma de Buenos Aires, Argentina.

E-mail address: carlosbosch73@gmail.com 